University of South Florida

DIGITAL COMMONS

Digital Commons @ University of

@ UNIVERSITY OF SOUTH FLORIDA

South Florida

Marine Science Faculty Publications

College of Marine Science

$11-15-1998$

\title{
An Empirical Algorithm for Light Absorption by Ocean Water Based on Color
}

\author{
ZhongPing Lee \\ University of South Florida \\ Kendall L. Carder \\ University of South Florida, kcarder@marine.usf.edu \\ R. G. Steward \\ University of South Florida \\ T. G. Peacock \\ University of South Florida \\ C. O. Davis \\ Naval Research Laboratory
}

See next page for additional authors

Follow this and additional works at: https://digitalcommons.usf.edu/msc_facpub

Part of the Marine Biology Commons

\section{Scholar Commons Citation}

Lee, ZhongPing; Carder, Kendall L.; Steward, R. G.; Peacock, T. G.; Davis, C. O.; and Patch, J. S., "An Empirical Algorithm for Light Absorption by Ocean Water Based on Color" (1998). Marine Science Faculty Publications. 7.

https://digitalcommons.usf.edu/msc_facpub/7

This Article is brought to you for free and open access by the College of Marine Science at Digital Commons @ University of South Florida. It has been accepted for inclusion in Marine Science Faculty Publications by an authorized administrator of Digital Commons @ University of South Florida. For more information, please contact digitalcommons@usf.edu. 


\section{Authors}

ZhongPing Lee, Kendall L. Carder, R. G. Steward, T. G. Peacock, C. O. Davis, and J. S. Patch 


\title{
An empirical algorithm for light absorption by ocean water based on color
}

\author{
Z. P. Lee, K. L. Carder, R. G. Steward, and T. G. Peacock \\ Department of Marine Science, University of South Florida, St. Petersburg \\ C. O. Davis \\ Naval Research Laboratory, Washington, D.C. \\ J. S. Patch \\ Department of Marine Science, University of South Florida, St. Petersburg
}

\begin{abstract}
Empirical algorithms for the total absorption coefficient and absorption coefficient by pigments for surface waters at $440 \mathrm{~nm}$ were developed by applying a quadratic formula that combines two spectral ratios of remote-sensing reflectance. For total absorption coefficients ranging from 0.02 to $2.0 \mathrm{~m}^{-1}$, a goodness of fit was achieved between the measured and modeled data with a root-mean-square difference between the measured and modeled values for $\log 10$ scale $\left(\mathrm{RMSD}_{\log 10}\right)$ of $0.062(15.3 \%$ for linear scale, number of samples $N=63)$, while RMSD log10 $_{10}$ is $0.111(29.1 \%$ for linear scale, $N=126$ ) for pigment absorption (ranging from 0.01 to $1.0 \mathrm{~m}^{-1}$ ). As alternatives to pigment concentration algorithms, the absorption algorithms developed can be applied to the coastal zone color scanner and sea-viewing wide-field-of-view sensor data to derive inherent optical properties of the ocean. For the same data sets, we also directly related the chlorophyll $a$ concentrations to the spectral ratios and obtained an RMSD $\mathrm{I}_{\log 10}$ value of $0.218(65.2 \%$ for linear scale, $N=120)$ for concentrations ranging from 0.06 to 50.0 $\mathrm{mg} \mathrm{m}^{-3}$. These results indicate that it is more accurate to estimate the absorption coefficients than the pigment concentrations from remotely sensed data. This is likely due to the fact that for the broad range of waters studied the pigment-specific absorption coefficient at $440 \mathrm{~nm}$ ranged from 0.02 to $0.2 \mathrm{~m}^{2}(\mathrm{mg} \mathrm{chl})^{-1}$. As an indirect test of the algorithms developed, the chlorophyll $a$ concentration algorithm is applied to an independent global data set and an $\mathrm{RMSD}_{\log 10}$ of $0.191(55.2 \%$ for linear scale, $N=919)$ is obtained. There is no independent global absorption data set available as yet to test the absorption algorithms.
\end{abstract}

\section{Introduction}

Since the late 1970 s, many empirical algorithms have been developed to estimate chlorophyll $a$ or pigment concentrations in open ocean and coastal waters [Morel and Prieur, 1977; Clark, 1981; Gordon and Morel, 1983; Gordon et al., 1983], but only a few algorithms have been developed for optical properties of the water. Applying a specific optical property (e.g., specific absorption coefficient), those concentrations can, however, be converted to absorption and/or attenuation coefficients [Gordon and Morel, 1983; Gordon et al., 1988; Morel, 1988; Carder et al., 1991]. As demonstrated earlier [Austin and Petzold, 1981; Mueller and Trees, 1990; Carder et al., 1992; Lee, 1994], in-water optical properties can be empirically derived from spectral ratios of water-leaving radiance or spectral ratios of remote-sensing reflectance in one step. To extend our early studies [Carder et al., 1992; Lee, 1994], total absorption coefficients at $440 \mathrm{~nm}$ [ $a,(440)$; see Table 1 for symbols used in this paper] for the upper water column and those for surface pigments are empirically related to the spectral ratios of remote-

Copyright 1998 by the American Geophysical Union.

Paper number $98 \mathrm{JC} 01946$.

0148-0227/98/98JC-01946\$09.00 sensing reflectance at the sea-viewing wide-field-of-view sensor (SeaWiFS) bands, which provide alternatives to the pigment concentration algorithms [e.g., Gordon and Morel, 1983] for deriving in-water optical information.

The total absorption coefficient of surface water, which dominates the variance of both remote-sensing reflectance and diffuse attenuation, is important to many aspects of oceanography (e.g., water-type classification, subsurface light intensity, heat flux, etc.). Empirical algorithms for estimating diffuse attenuation coefficients from reflectance, based on in-water measurements, have been developed [Austin and Petzold, 1981; Mueller and Trees, 1990]. As the relationship between remotesensing reflectance and absorption only weakly depends on the solar elevation [Morel and Gentili, 1993], the spectral ratios of remote-sensing reflectance should then be almost independent of solar and/or view angles. This suggests that inherent optical properties [Preisendorfer, 1976] such as the total absorption coefficients might be derived from the spectral ratios of remote-sensing reflectance. Since pigment absorption peaks near $440 \mathrm{~nm}$, the values of $a_{t}(440)$ are empirically related to various spectral ratios of remote-sensing reflectance in this study. Actually, field data show that optical properties at $440 \mathrm{~nm}$ and other wavelengths [e.g., $K_{d}(440)$ and $K_{d}(490), c(440)$ and $c(490)$ ] are correlated [Austin and Petzold, 1986; Voss, 1992]. 
Table 1. Definitions of Symbols

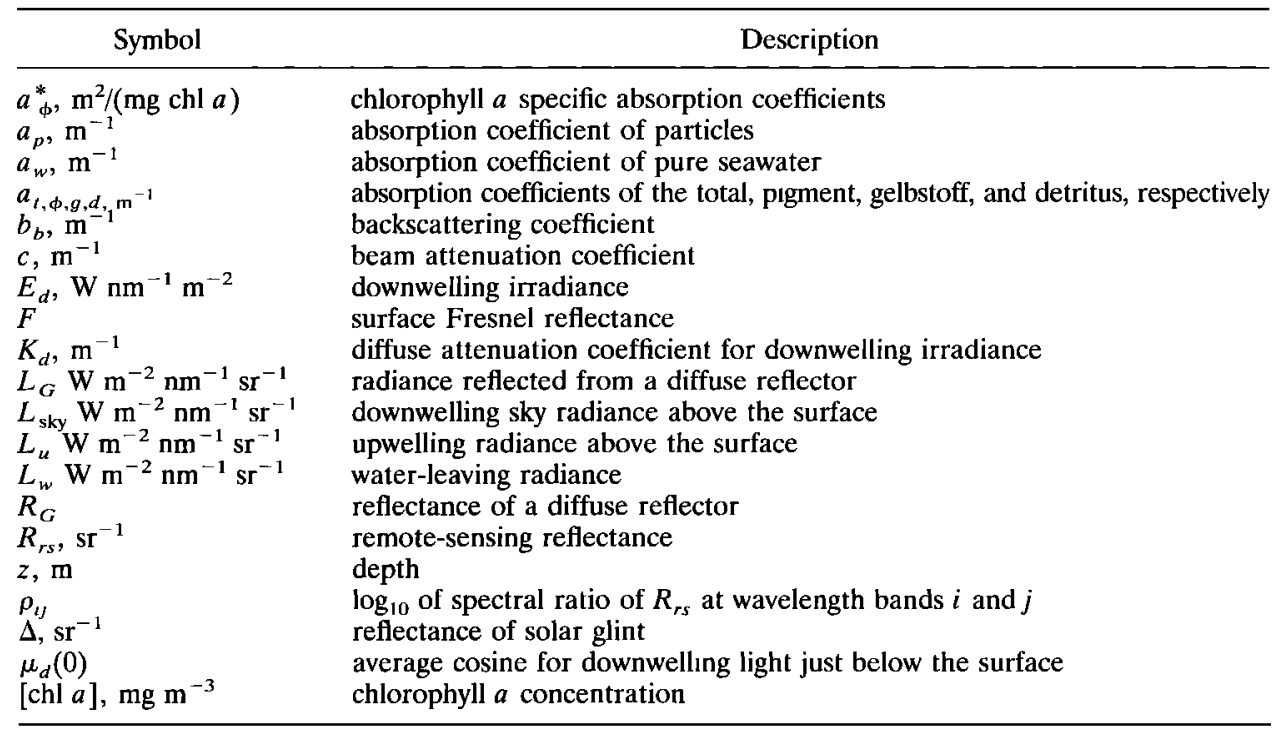

The pigment absorption coefficient is important for the calculation of light harvesting by phytoplankton for use in primary production models [e.g., Platt and Sathyendranath, 1988; Smith et al., 1989; Lee et al., 1996a] and for determination of the chlorophyll $a$ /pigment concentrations (e.g., K. L. Carder et al., Semi-analytic MODIS algorithms for chlorophyll $a$ and absorption with bio-optical domains based on nitrate-depletion temperatures, submitted to Journal of Geophysical Research, 1998) (hereinafter referred to as submitted manuscript, 1998). Traditional remote-sensing methods have estimated pigment absorption using the following two steps: (1) derive chlorophyll $a$ or pigment concentration from empirical remote-sensing algorithms [e.g., Gordon et al., 1983; Morel, 1996] and (2) convert the concentration values to absorption values using known or assumed chlorophyll-specific absorption coefficients [Morel, 1988; Carder et al., 1991]. That perhaps accounts for the different empirical and semianalytical algorithms developed for remote sensing of pigment concentrations [Morel and Prieur, 1977; Gordon et al., 1983; Garver and Siegel, 1997; Carder et al., submitted manuscript, 1998]. We may, however, obtain the pigment absorption coefficients directly from the remotely measured data as briefly indicated by Lee et al. [1996a]. This type of algorithm may be applied to a wider range of oceanic environments than the two-step algorithms, since the chlorophyll-specific absorption coefficient is not involved and it varies widely from place to place [Morel and Bricaud, 1981; Sathyendranath et al., 1987].

Analytical methods have been developed for the derivation of oceanic absorption coefficients from above-surface remotesensing reflectance [Lee, 1994; Lee et al., 1996b] or subsurface irradiance reflectance [Roesler and Perry, 1995]. The methods use optimization [Lee et al., 1996b] or multiple regression [Roesler and Perry, 1995] approaches, which require hyperspectral data and would take a rather long calculation time for processing of satellite images. They are, however, more accurate in decomposing the total absorption coefficients into those of pigment and gelbstoff (i.e., yellow substance or colored dissolved organic matter). For image-processing purposes, more rapid algorithms are needed, though they may be less accurate. Recently, Hoge and Lyon [1996] suggested a matrix inversion technique. The technique requires, however, pre- knowledge of the spectral models of the inherent optical properties, and the method has not been tested with field data.

"In this study, empirical algorithms are developed for quickly estimating the total and pigment absorption coefficients at 440 $\mathrm{nm}$ by directly relating them to the spectral ratios of remotesensing reflectance at two or three wavelength bands. Table 2 provides wavelength band information. In order to obtain a better goodness of fit between measured and algorithmderived data, we adopt a formula of quadratic polynomials using two spectral ratios. With derived absorption coefficients at $440 \mathrm{~nm}$, the absorption spectrum for pigment and the total in the visible domain can be constructed using the approaches of Austin and Petzold [1986], Carder et al. [1991], Lee [1994], Bricaud et al. [1995], and/or Roesler and Perry [1995].

Since regression-based algorithms are only appropriate to waters with characteristics similar to those in the development data set, we must also evaluate how universal the algorithms are that are so derived. As an indirect test of the applicability of the developed algorithms to the global ocean, the chlorophyll $a$ (chl $a$ ) algorithm was applied to a global chlorophyll data set [O'Reilly et al., 1998] and a root-mean-square difference for $\log _{10}$ scale (RMSD ${ }_{\text {log } 10}$ ) of 0.191 (55.2\% for linear scale, $N=919$ ) was obtained. There is no independent absorption data set available to test the absorption algorithms yet, but the accuracy of the chlorophyll retrievals is consistent with the independent algorithms tested by O'Reilly et al. [1998].

\section{Approach}

A quadratic type of formula was selected for our empirical remote-sensing algorithm for absorption coefficients and pig-

Table 2. Wavelength Band Definitions

\begin{tabular}{cc}
\hline Band & Wavelength, nm \\
\hline 1 & 410 \\
2 & 440 \\
3 & 490 \\
4 & 510 \\
5 & 555 \\
\hline
\end{tabular}


Table 3. Data Information

\begin{tabular}{|c|c|c|c|c|}
\hline Cruise & Area & Time & Data & $\begin{array}{c}\text { Maximum Number } \\
\text { of Data Pairs }\end{array}$ \\
\hline MB & Monterey Bay & Sept., Oct. 1989 & $R_{, \ldots}, a_{t}, a_{\phi},[\operatorname{chl} a]$ & 9 \\
\hline MLML 2 & North Atlantic & Aug. 1991 & $R, a_{b},[\mathrm{chl} a]$ & 10 \\
\hline СР9204 & Gulf of Mexico & Oct. 1992 & $R_{r b}, a_{\phi},[\operatorname{chl} a]$ & 17 \\
\hline GOMEX & Gulf of Mexico & April 1993 & $R_{r s}, a_{t}, a_{\phi},[\operatorname{chl} a]$ & 25 \\
\hline COLOR & Gulf of Mexico & June 1993 & $R_{r b}, a_{i}, a_{\phi},[\operatorname{chl} a]$ & 14 \\
\hline TN042 & Arabian Sea & Nov.-Dec. 1994 & $R_{r l}, a_{r}, a_{\phi},[\operatorname{chl} a]$ & 20 \\
\hline BER & Bering Sea & April 1996 & $R_{r b}, a_{b b},[\operatorname{chl} a]$ & 35 \\
\hline
\end{tabular}

See Table 1 for variable definitions.

ment concentrations, based upon its performance, heuristical arguments by Aiken et al. [1995], and arguments by $O$ 'Reilly $e t$ al. [1998]. We use two spectral ratios in the calculation to increase the range of algorithm sensitivity to both high- and low-absorption values. The calculations take the form,

$$
\log _{10}(Q)=A_{0}+A_{1} \rho_{l j}+A_{2} \rho_{i j}^{2}+B_{1} \rho_{k l}+B_{2} \rho_{k l}^{2},
$$

where $Q$ represents the quantities $a_{t, \phi}(440), K_{d}$, or [chl $a$ ]. Subscripts $t$ and $\phi$ are for total water constituents and pigments, respectively; $\rho_{t \jmath, k l}$ is the $\log _{10}$ transform of spectral ratio of remote-sensing reflectance $R_{r s}$ at two wavelengths to provide sensitivity over several orders of variation. Thus

$$
\rho_{l j}=\log _{10}\left[\frac{R_{r s}\left(\lambda_{l}\right)}{R_{r s}\left(\lambda_{j}\right)}\right], \quad \rho_{k l}=\log _{10}\left[\frac{R_{r s}\left(\lambda_{k}\right)}{R_{r s}\left(\lambda_{l}\right)}\right] .
$$

$A$ and $B$ values in (1) are the derived regression coefficients for each quantity $Q$. The second-order polynomial with two spectral ratios not only provides sensitivity over a wide range of water types but also helps separate the effects of gelbstoff absorption from that of phytoplankton pigments.

\section{Data Sets and Measurements}

Data used in this study came from a variety of oceanic and coastal environments, with a wide range of water types. Table 3 provides the time and location information regarding these data, while Figure 1 shows the locations on a global map.

For each station, remote-sensing reflectance, total absorption coefficients of the upper water column, pigment absorption coefficients, and chlorophyll $a$ concentrations of water samples were measured. Methods for each measurement are briefly described below.

\subsection{Remote-Sensing Reflectance $\boldsymbol{R}_{r s}(\boldsymbol{\lambda})$}

$R_{r s}$ is defined as the ratio of the water-leaving radiance $L_{w}$ to the downwelling irradiance $E_{d}$ just above the surface [Carder and Steward, 1985]. As $L_{w}$ cannot be directly measured from above the surface, $R_{r s}$ was determined by correcting for the surface-reflected skylight and solar glint from the measured above-surface total reflectance, using a method extending the approach of Carder and Steward [1985]. Briefly, for each field station, using a Spectron Engineering spectroradiometer (Spectron model SE-590), a series (normally three to five scans) of upwelling radiance above the surface $\left[L_{u}\left(0^{+}, \theta_{a}\right.\right.$, $\varphi)]$ and downwelling sky radiance $\left(L_{s k y}\left(\theta^{\prime}, \varphi\right)\right)$ data were collected, with $\theta_{a} \sim 30^{\circ}$ from nadir and $\varphi$ about $90^{\circ}$ from the solar plane. Sky radiance was measured in the same plane as $L_{u}\left(0^{+}\right)$but from a direction of $\theta^{\prime} \sim 30^{\circ}$ from zenith. Downwelling irradiance was derived by measuring the radiance $L_{G}$ reflected from a standard diffuse reflector (Spectralon). For each of the collected scans, total remote-sensing reflectance $T_{r s}$ and sky input $S_{r s}$ were derived through

$$
T_{r s}=\frac{L_{u}}{L_{G}} \frac{R_{G}}{\pi}, S_{r s}=\frac{L_{\text {sky }}}{L_{G}} \frac{R_{G}}{\pi},
$$

where $R_{G}$ is the reflectance of the diffuse reflector $(\sim 10 \%)$.

In order to reduce the influence of the uneven sea surface, averages of $T_{r s}$ and $S_{r s}$ were derived from the measured $T_{r s}$ and $S_{r s}$ curves, respectively. From the averaged $T_{r s}$ and $S_{r s}$, $R_{r s}$ is derived by the following formula:

$$
R_{r s}(\lambda)=T_{r s}(\lambda)-F S_{r s}(\lambda)-\Delta
$$

where $F$ is surface Fresnel reflectance $\left(0.022\right.$ for $\left.\theta_{a} \sim 30^{\circ}\right) ; \Delta$ is for solar glint effects and is determined by assuming $R_{r s}(750)=0$ for open ocean waters or iteratively estimated for coastal turbid waters [Lee et al., 1996c].

\subsection{Total Absorption Coefficient $a_{t}(\boldsymbol{\lambda})$}

In our field measurements, there was no instrument to measure the in situ total absorption coefficient. The vertical profiles of the downwelling and upwelling irradiance, however, were measured. Recently, Gordon and Boynton [1997] suggested a Monte Carlo approach to derive the total absorption coefficients from the irradiance profiles. The method provided accurate retrieval of the total absorption coefficients for the computer simulated data but has not been tested in the natural field.

As indicated by Lee et al. [1996b], we derived the total absorption coefficient from the downwelling diffuse attenuation coefficient of the upper water column, using a simplified analytical formula similar to that of Morel and Prieur [1975]. Basically, from Monte Carlo simulations [Gordon, 1989, equations (9) and (10)],

$$
a_{b}(\lambda)+b_{b}(\lambda) \approx f \mu_{d}(0, \lambda) K_{d}(\lambda),
$$

where $K_{d}$ is the downwelling diffuse attenuation coefficient; $\mu_{d}$, the average cosine for downwelling light, is the ratio of downwelling photons passing through a horizontal area $X$ to the downwelling photons passing through a sphere of cross section $X ; \mu_{d}(0, \lambda)$ is the $\mu_{d}$ value evaluated just beneath the surface for wavelength $\lambda$ [Gordon, 1989]. For Sun angles varying from 0 to $70^{\circ}$ from zenith, $\mu_{d}(0,440) / \mu_{d}(0,550)$ varied by, at most, about 5\% (Figure 2 and Gordon [1989, Table 3]), which suggests $\mu_{d}(0, \lambda)$ is a weak function of wavelength [Morel and Prieur, 1975]. For clear-sky days, $\mu_{d}(0)$ approximates $\cos (j)$ [Gordon, 1989], where $j$ is the subsurface solar zenith angle. Here $f$ is a factor to account for the possible 


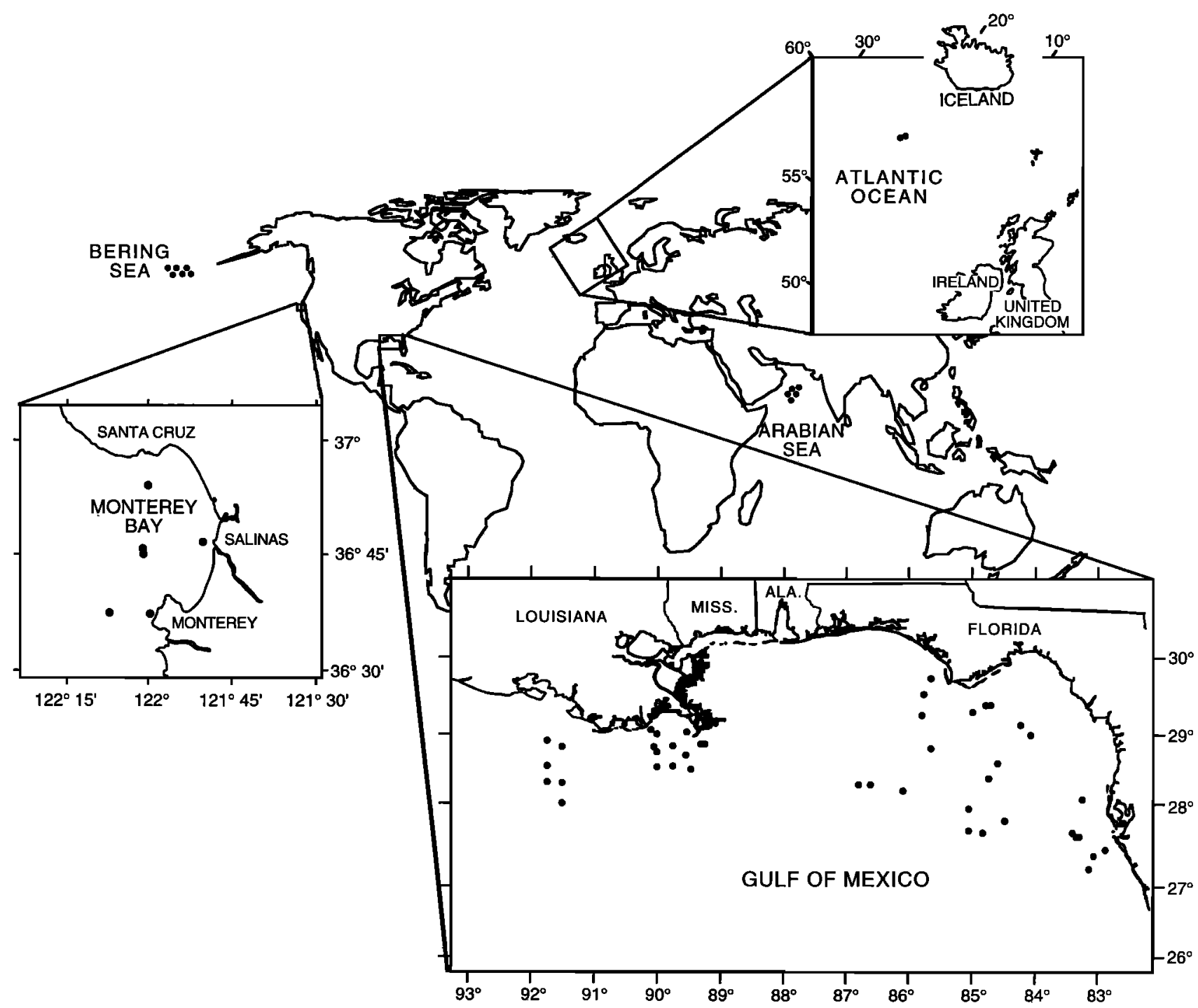

Figure 1. Data locations.

changes of the average cosine with increasing depth. For subsurface $K_{d}, f$ is about 1.0395 [Gordon, 1989], and it is about 0.93 for the average $K_{d}$ of the entire euphotic zone.

From Morel and Gentili [1993], for most coastal and oceanic waters,

$$
R_{r} \approx 0.05 \frac{b_{b}}{a_{t}}
$$

or

$$
b_{b} \approx 20.0 a, R_{r s}
$$

Thus, at least to first order,

$$
a_{t}(\lambda) \approx \frac{f \mu_{d}(0) K_{d}(\lambda)}{1+20.0 R_{r s}(\lambda)} .
$$

Therefore $K_{d}$ and $\mu_{d}(0)$ must be estimated in order to derive $a_{t}$ using (8), given an $R_{r s}$ measurement.

The process of deriving $K_{d}$ is similar to that given by Smith and Baker [1981]. Briefly, for the upper water column,

$$
E_{d}(z)=E_{d}\left(0^{-}\right) e^{-K_{d}(z},
$$

$$
\ln \left[E_{d}(z)\right]=\ln \left[E_{d}\left(0^{-}\right)\right]-K_{d} z .
$$

There are only two unknowns, $E_{d}\left(0^{-}\right)$and $K_{d}$, in (10). However, owing to effects from wave focusing and ship shadow [Gordon, 1985], the measured $E_{d}(z)$ and $z$ include errors associated with the field, so we cannot simply use values from two depths to derive $K_{d}$ and $E_{d}\left(0^{-}\right)$. In order to reduce those influences, linear regression between $\ln \left[E_{d}(z)\right]$ and $z$ was performed for the surface layer. The regression results provide $K_{\text {l. }}$.

Since clear-sky days are not always available for field measurements and there is some influence due to the ship presence [Gordon, 1985], it is not always easy to get the correct $\mu_{d}(0)$ for all field situations. In this case, to calculate $a_{t}$ using (8), an effective $\mu_{d}\left[=f \mu_{d}(0)\right]$ for each station was derived by forcing the $K_{d}$-derived $a_{t}(\lambda)$ to match $a_{w}(\lambda)+a_{p}(\lambda)$ for $\lambda$ in the range of $620-660 \mathrm{~nm}$, where the total absorption coefficients are dominated by the water molecules. In this way, errors due to sea-surface roughness and ship presence can be reduced, and $\mu_{d}$ can be estimated for patchy cloudy days when the subsurface angle $j$ is uncertain. The $a_{w}(\lambda)$ values of Smith and 


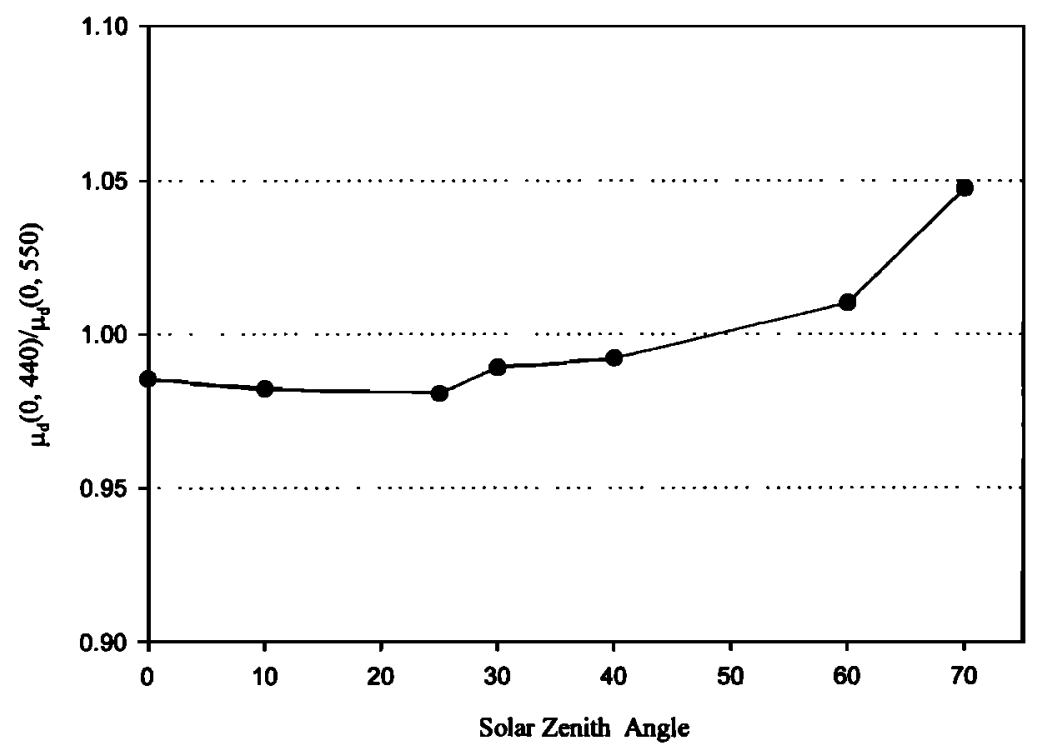

Figure 2. Ratios of subsurface downwelling average cosine at 440 and $550 \mathrm{~nm}$ for different Sun angles (based on Gordon [1989]).

Baker [1981] were used along with measured $a_{p}(\lambda)$. For most ocean waters, gelbstoff absorption is negligible for $\lambda>620 \mathrm{~nm}$.

The vertical profiles of the downwelling irradiance $\left[E_{d}(z)\right]$ were measured using a Biospherical Instruments MER (model 1048A), which was deployed about $5 \mathrm{~m}$ away from the ship to reduce the ship-shadow effects [Mueller and Austin, 1992]. An added advantage of using $K_{d}$ to measure $a_{t}$ is that $K_{d}$ can be determined over a long path length (e.g., $10-15 \mathrm{~m}$ ) for extremely clear waters where absorption coefficients as small as $0.02 \mathrm{~m}^{-1}$ must be quantified.

\subsection{Pigment Absorption Coefficient $a_{\phi}(\lambda)$}

The $a_{\phi}(\lambda)$ was measured following the SeaWiFS protocols [Mueller and Austin, 1992]. Basically, water samples were collected from the surface layer (about $5 \mathrm{~m}$ below surface). The method described by Mitchell and Kiefer [1988] was used to measure the particle absorption coefficients on Whatman glass-fiber (GF/F) filter pads $\left(a_{p}\right)$, and the method developed by Kishino et al. [1985] and modified by Roesler et al. [1989] was used to measure the detritus absorption on the pad $\left(a_{d}\right)$ in order to calculate the phytoplankton absorption coefficient $a_{\phi}$. The " $\beta$ factor" from Bricaud and Stramski [1990, equation (2)], for the correction of the optical-path elongation due to filterpad multiple scattering, was used for the calculations of $a_{p}$ and $a_{d}$. The measured $a_{p}(\lambda)$ or $a_{d}(\lambda)$ spectra were derived by adjusting the calculated $a_{p}(\lambda)$ or $a_{d}(\lambda)$ until $a_{p}(780)=0$ or $a_{d}(780)=0$, respectively. The difference between the particle and detrital absorption coefficients provided the absorption coefficient of phytoplankton pigments $a_{\phi}$ :

$$
a_{\phi}=a_{p}-a_{d}
$$

\subsection{Chlorophyll $a$ Concentration [chl $a$ ]}

Concentrations of chlorophyll $a$ were measured fluorometrically from collected surface water samples, using the standard acidification technique [Yentsch and Menzel, 1963; HolmHansen and Riemann, 1978] on a Turner Designs 10-AU fluorometer. For details, see Bissett et al. [1997].

\section{Results and Discussion}

Statistical analyses were performed between the $\log _{10}$ transforms of the parameters of interest and the $\log _{10}$ transforms of the spectral ratios of the remote-sensing reflectance. Results are presented in Table 4 . The coefficients (values of $A$ and $B$ ) of the empirical algorithms for $a_{t}(440), a_{\phi}(440)$, and [chl $\left.a\right]$ were derived when RMSD $_{\log 10}$ (root-mean-square difference in $\log _{10}$ scale) was minimized. $R M$ MSD $_{\log 10}$ was calculated as

$\mathrm{RMSD}_{\log 10}=\sqrt{\frac{\sum_{n=1}^{N}\left[\log _{10}\left(Q_{n}^{\text {reg }}\right)-\log _{10}\left(Q_{n}^{\text {mea }}\right)\right]^{2}}{N}}$,

where superscripts "reg" and "mea" indicate values determined using the regression equation and measurements, respectively, and which suggests the difference in linear scale is

$$
\varepsilon=10^{\mathrm{RMSD}_{\log 10}}-1 \text {. }
$$

Here $Q_{n}$ is the $n$th value of the quantity $Q$ [e.g., $a_{t}(440)$, etc.] and $N$ is the total number of $Q$ values in the study. The above

Table 4. Linear Correlation Coefficients $r^{2}$ Between the Variables and the Ratios After $\log _{10}$ Transformation

\begin{tabular}{lccccr}
\hline & $\rho_{15}$ & $\rho_{25}$ & $\rho_{35}$ & $\rho_{45}$ & $N$ \\
\hline $\log _{10}\left[a_{r}(440)\right]$ & 0.928 & 0.963 & 0.975 & 0.978 & 63 \\
$\log _{10}\left[a_{\phi}(440)\right]$ & 0.711 & 0.810 & 0.901 & 0.916 & 126 \\
$\log _{10}(\operatorname{chl} a)$ & 0.760 & 0.830 & 0.883 & 0.868 & 120 \\
\hline
\end{tabular}

$N$ is number of samples. 

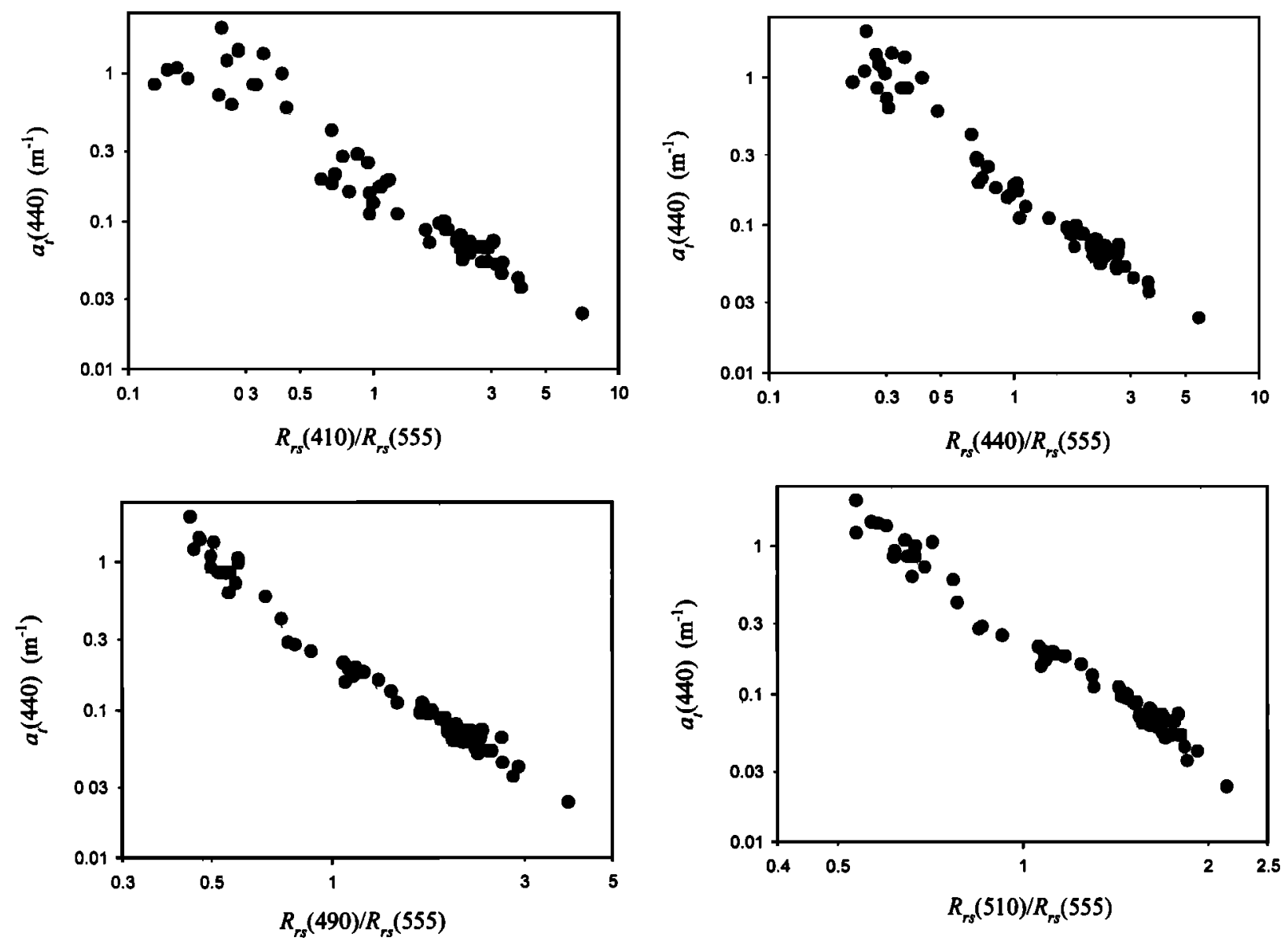

Figure 3. Total absorption coefficient $a_{t}(440)$ versus spectral ratios of remote-sensing reflectance $R_{r s}$.

method of difference calculation provides a measure of goodness of fit between the measured and modeled data, with an emphasis that an equally large fractional error occurs for underestimation and for overestimation over the entire large range of individual values. For example, differences are the same $\left(\mathrm{RMSD}_{\log 10}=0.477\right)$ for $Q_{n}^{\text {reg }} / Q_{n}^{\text {mea }}=1 / 3$ and for $Q_{n}^{\text {reg }} / Q_{n}^{\text {mea }}=3.0$. However, traditional linear root-meansquare error estimates $67 \%$ for $Q_{n}^{\text {reg }} / Q_{n}^{\text {mea }}=1 / 3$ and $200 \%$ for $Q_{n}^{\text {reg }} / Q_{n}^{\text {mea }}=3.0$, indicating that overestimates contribute much more to the error than underestimates.

\subsection{Total Absorption Coefficient at $440 \mathrm{~nm}, a_{t}(\mathbf{4 4 0})$}

From Table 4 and Figure 3, it is interesting to note that with $a_{t}(440)$ values ranging over 2 orders of magnitude, $\log _{10}\left[a_{t}(440)\right]$ was highly correlated with all $\rho_{i j}$ but most significantly with $\rho_{35}$ and $\rho_{45}$. This probably expresses the fact that for very absorbing waters, $R_{r s}(410)$ and $R_{r s}(440)$ are very close to zero, where increases in absorption make a negligible change on $R_{r}(\lambda)$ values relative to any noise in the data. We refer to this as algorithm saturation. On the other hand, for very low absorption values, $R_{r, s}(410)$ and $R_{r,}(440)$ are much more sensitive to changes in absorption than are $R_{r s}(490)$ and $R_{r,}(510)$. Also note that the $\log _{10}\left[a_{r}(440)\right]$ and $\rho_{l j}$ values are not exactly linearly related but appear curved about values of $a_{t}(440)=0.2 \mathrm{~m}^{-1}$. This suggests that two different $a_{t}(440)$ algorithms might need to be developed if we just linearly relate $\log _{10}\left[a_{t}(440)\right]$ to the $\log _{10}$ of one spectral ratio. Comparing the correlation coefficients $r^{2}$ of $\log _{10}$ $\left[a_{\phi}(440)\right]$ versus $\rho_{l j}$ and that of $\log _{10}\left[a_{t}(440)\right]$ versus $\rho_{l j}$ clearly indicates that remote-sensing signals are a strong function of the total absorption but a weaker function of an individual component. Regarding the lower $r^{2}$ values for $\log _{10}$ [ $\left.a_{t}(440)\right]$ versus $\rho_{15}$, most of the disagreement occurred when $\rho_{15}$ was small or where $R_{r s}(410)$ was small for highly absorbing coastal waters, suggesting algorithm saturation.

To examine algorithm forms more amenable to the curvature expressed in Figure 3 and less sensitive to algorithm saturation, we used (1), combining $\rho_{25}$ and $\rho_{35}$. An $a_{t}$ (440) algorithm was derived as

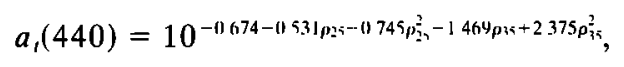

with RMSD $_{\log 10}=0.062(\varepsilon=15.3 \%)$. Also, by combination of $\rho_{35}$ and $\rho_{45}$, we obtain

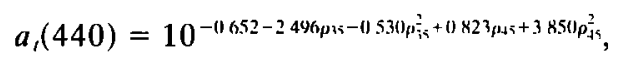

with $\mathrm{RMSD}_{\log 10}=0.062(\varepsilon=15.3 \%)$, too.

The residual difference includes both errors from the derivation of $a_{t}(440)$ [e.g., (8)] and those associated with the empirical approach used here. Figure 6a shows measured $a_{t}$ (440) values versus those determined using (14).

When only either $\rho_{35}$ or $\rho_{45}$ ratios exist, we obtain

$$
a_{i}(440)=10^{-0.619-1969 \rho_{35}+0790 \rho_{35}^{2}}
$$

with $\mathrm{RMSD}_{\log 10}=0.068(\varepsilon=16.9 \%)$, or 

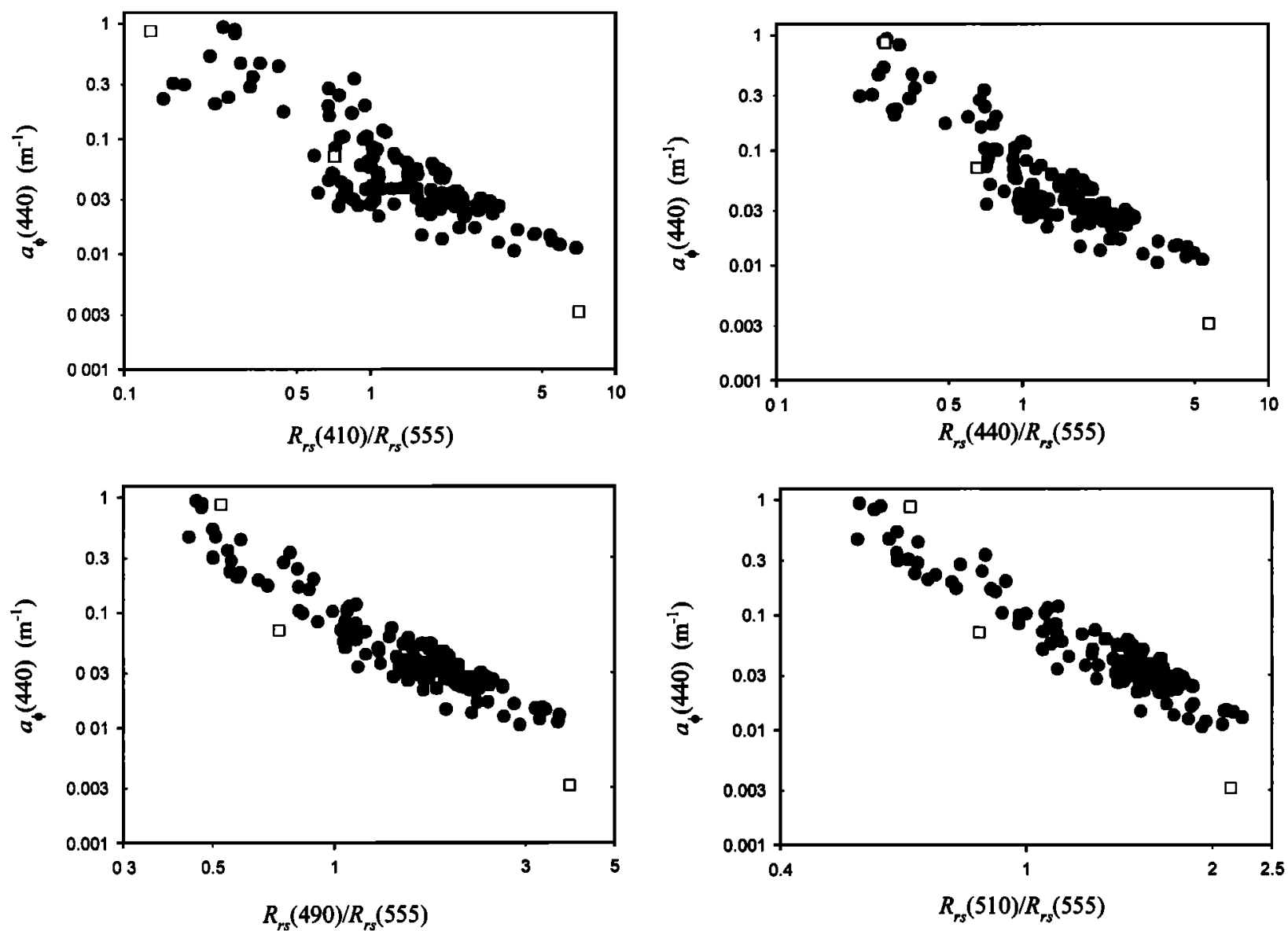

Figure 4. Pigment absorption coefficient $a_{\phi}(440)$ versus spectral ratios of $R_{r s}$. (Three points (squares) were not used in the algorithm development.)

$$
a_{t}(440)=10^{-0600-2811 \rho_{45}+0642 \rho_{45}^{2}}
$$

with $\mathrm{RMSD}_{\log 10}=0.075(\varepsilon=18.9 \%)$. These results indicate the improvement in empirically fitting the measured data by the combination of two ratios, though the quadratic polynomial and the two ratios make (14) appear more complicated than any simple linear regression.

If we drop the second-order term polynomial in (16) or (17), larger $\mathrm{RMSD}_{\log 10}$ values result. For instance, $\mathrm{RMSD}_{\log 10}=$ $0.080(\varepsilon=20.2 \%)$ in using $\rho_{35}$ without the second-order polynomial, which suggests a $17.6 \%$ increase in RMSD $_{\log 10}$ values compared with (16) or $19.5 \%$ increase in $\varepsilon$ values. Combinations of three or more spectral ratios were tested, but no significant improvement was found in reducing the value of RMSD $_{\log 10}$.

Comparing the RMSD $D_{\log 10}$ values obtained with (14)-(17), we see that the ratio $\rho_{35}$ is quite a good indicator of $a_{t}(440)$. Considering the wide variety of waters covered, a value of 0.062 for $\mathrm{RMSD}_{\log 10}(15.3 \%$ for linear scale; see (14)) is quite small, which suggests possible applications of (14) or (15) to different parts of the world ocean. Heuristically, (14) is more sensitive to variations in clear waters, while (15) is more sensitive to variations in eutrophic waters.

In earlier studies, it was found that diffuse attenuation coefficients were empirically related to ratios of water-leaving radiance [Austin and Petzold, 1981; Mueller and Trees, 1990], using a formula such as

$$
K(\lambda)=A\left[\frac{L_{w}\left(\lambda_{1}\right)}{L_{w}\left(\lambda_{2}\right)}\right]^{B} .
$$

On the basis of the definition of $R_{r s}$ [Gordon et al., 1980; Carder and Steward, 1985], (18) can be expressed as

$$
K(\lambda)=A\left[\frac{R_{r s}\left(\lambda_{1}\right)}{R_{r s}\left(\lambda_{2}\right)} \frac{E_{d}\left(\lambda_{1}\right)}{E_{d}\left(\lambda_{2}\right)}\right]^{B} .
$$

Since $K(\lambda)$ and $E_{d}\left(\lambda_{1}\right) / E_{d}\left(\lambda_{2}\right)$ each is affected differently by the distribution of the subsurface light field [Gordon, 1989; Kirk, 1984, 1991], we may expect more data scatter (less correlation) in the $K$ versus $L_{w}$ approach (equation (18)) than in the $a_{t}$ versus $R_{r s}$ approach. This conclusion is supported by the data sets of this study, where the smallest $\mathrm{RMSD}_{\log 10}$ value obtained was 0.089 (22.7\% in linear scale) for $K_{d}(440)$ by using (1), whereas it is 0.062 for (14) or (15).

\subsection{Pigment Absorption Coefficient at $440 \mathrm{~nm}, a_{\phi}(440)$}

For $a_{\phi}(440)$ values ranging from 0.01 to $1.0 \mathrm{~m}^{-1}, \log _{10}$ $\left[a_{\phi}(440)\right]$ values were more highly correlated with $\rho_{35}$ and $\rho_{45}$ than with $\rho_{15}$ and $\rho_{25}$ (Figure 4 and Table 4). This is likely due to the greater gelbstoff influence on $\rho_{15}$ and $\rho_{25}$ than on $\rho_{35}$ and $\rho_{45}$, especially as many of the water samples came from "case 2" waters [Gordon and Morel, 1983].

For this study, an empirical algorithm for $a_{\phi}(440)$ is obtained by a combination of $\rho_{25}$ and $\rho_{35}$, 

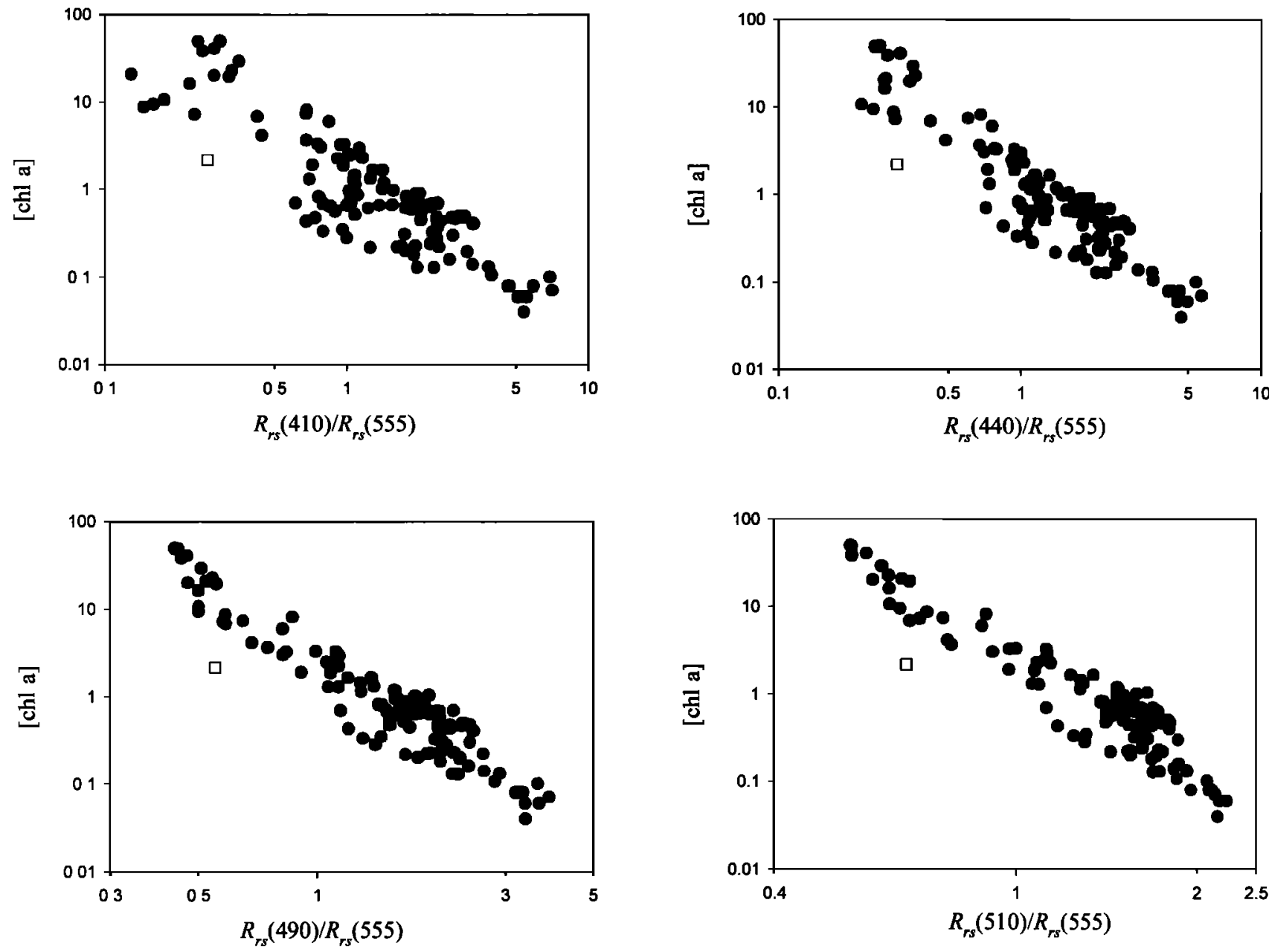

Figure 5. Chlorophyll $a$ concentrations [chl $a$ ] versus the spectral ratios of $R_{r s}$. (One point) (square) was not used in algorithm development.)

$$
a_{\phi}(440)=10^{-0919+10107 p_{2 i}-04407 \rho_{25}^{2}-3531 \rho_{35}+1579 \rho_{35}^{2},}
$$

with $\mathrm{RMSD}_{\log 10}=0.111(\varepsilon=29.1 \%)$. Figure 6b shows measured $a_{\phi}(440)$ values versus those determined using (20). This indicates that although individually, $\rho_{35}$ or $\rho_{45}$ is more highly correlated with $\log _{10}\left[a_{\phi}(440)\right]$, the combination of $\rho_{25}$ and $\rho_{35}$ compensates for some of the gelbstoff influence and provides more sensitivity to $a_{\phi}(440)$ for clear waters.

Not surprisingly, we got a larger RMSD $_{\log 11)}$ value for $a_{d,}(440)$ than for $a_{t}(440)$, becausc $\rho_{\| \prime}$ values are affected by all absorbing components in the water. By definition [Gordon et al., 1980; Carder et al., 1991],

$$
a_{r}(\lambda) \equiv a_{w}(\lambda)+a_{\phi}(\lambda)+a_{r j}(\lambda)+a_{r l}(\lambda) .
$$

The derivation of $a_{\phi}(440)$ from remote-sensing data is a result of spectrally decomposing $a_{,}(440)$. For the same $a_{i}(440)$ values, however, we can have quite different mixtures of $a_{\phi}(440)$ and $a_{g}(440)$ values, especially for non-"case 1" waters [Gordon and Morel, 1983], where, in theory, little correlation between $a_{\phi}(440)$ and $a_{g}(440)$ would be expected.

The greater $\mathrm{RMSD}_{\log 10}$ value for the $a_{\phi}(440)$ algorithm is partly due to natural variations of the $\beta$ factor used in $a_{\phi}(440)$ measurements. As pointed out by many researchers [e.g., Mitchell and Kiefer, 1988; Bricaud and Stramski, 1990; Nelson and Robertson, 1993; Moore et al., 1995], $\beta$ factors vary quite widely, especially when optical densities are low on the pad [Mitchell and Kiefer, 1988]. As more accurate methods of $a_{\phi}(\lambda)$ measurement become available, $(20)$ may be somewhat improved. Thus, if we keep in mind the uncertainties associated with $a_{\phi}(\lambda)$ measurements, a 0.111 value for RMSD $_{\log 10}$ for over 2 orders of magnitude range of $a_{\phi}(440)$ is really quite small, especially in comparison to the accuracy of most [chl $a$ ] algorithms (see below).

As with $a_{t}(440), a_{\phi}(440)$ can be related to single ratios, though larger RMSD $_{\log 10}$ values will result. For instance,

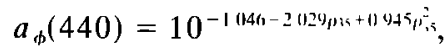

with $\mathrm{RMSD}_{\log 10}=0.128(\varepsilon=34.3 \%)$. Or,

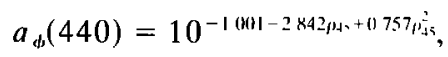

with $\mathrm{RMSD}_{\log 10}=0.126(\varepsilon=33.7 \%)$. Without the secondorder polynomial, $\mathrm{RMSD}_{\text {log } 10}$ value using $\rho_{35}$ would be 0.138 $(\varepsilon=37.4 \%)$.

For the empirical $a_{\phi}(\lambda)$ algorithms (see (20), (22), and (23)), values where $a_{\phi}(440)$ was less than $0.01 \mathrm{~m}^{-1}$ (one station) and there were strongly stratified waters (two stations) were not included (denoted by squares in Figure 4). For the case where $a_{\phi}(440)<0.01 \mathrm{~m}^{-1}$, the $a_{\phi}(\lambda)$ values for the green wavelengths were negative, which may be due to invalid 
measurements of $a_{p}(\lambda)$ and/or $a_{d}(\lambda)$ for the sample, due to low or nonuniform pad loading or optical density.

\subsection{Chlorophyll $a$ concentration [chl $a$ ]}

Our results are similar to the observations of Aiken et al. $[1995]$ in that $[\mathrm{chl} a]$ is strongly correlated with $\rho_{25}, \rho_{35}$, and $\rho_{45}$ (Figure 5). An empirical algorithm for [chl $a]$ is

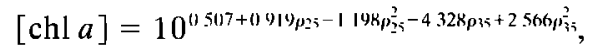

with $\mathrm{RMSD}_{\log 10}=0.218(\varepsilon=65.2 \%)$. Figure 6c shows measured $[\mathrm{chl} a]$ values versus those determined by (24).

For a single ratio,

$$
[\mathrm{chl} a]=10^{0.390-2716 \rho_{34}+0237 \rho_{14}^{2}}
$$

with $\operatorname{RMSD}_{\log 10}=0.228(\varepsilon=69.0 \%)$. For this $[\mathrm{chl} a]$ and $R_{r s}$ data set, $\mathrm{RMSD}_{\log 10}$ value is 0.229 if we drop the second-order polynomial in (25).

Comparing the RMSD Iog 10 values for $[\mathrm{chl} a$ ] to that for $a_{\phi}(440)$, note that for the same data set, the $\mathrm{RMSD}_{\log 10}$ value for $\left[\right.$ chl $a$ ] is much larger (a factor of $\sim 2$ ) than for $a_{\phi}(440)$. This is explained mathematically by the relationship,

$$
[\operatorname{chl} a]=a_{\phi}(440) / a_{\phi}^{*}(440) .
$$

The chlorophyll $a$ specific absorption coefficient, $a_{\phi}^{*}(440)$, is not a constant but varies by a factor of 5 or more [e.g., Morel and Bricaud, 1981; Sathyendranath et al., 1987; Bricaud et al., 1988; Stramski and Morel, 1990]. The fact that error in derived [chl $a$ ] is only twice that of derived $a_{\phi}(440)$ suggests that some of the variability in $a_{\phi}^{*}(440)$ covaries with [chl $a$ ]. Figure 7 shows the $a_{\phi}^{*}(440)$ values for this study, which ranged from 0.02 to $0.2 \mathrm{~m}^{2}$ (mg chl) ${ }^{-1}$ (except for one station with $a_{\phi}^{*}(440)$ $\left.<0.01 \mathrm{~m}^{2}(\mathrm{mg} \mathrm{chl})^{-1}\right)$. These values are consistent with values found in the literature [e.g., Bricaud et al., 1988, 1995]. Because of this variation in $a_{\phi}^{*}(440)$, the accuracy of estimating [chl $a$ ] will always be less than the accuracy of estimating $a_{\phi}(440)$ from remote sensing. This is not surprising since for our data set, [chl $a$ ] varied over 3 orders of magnitude, while $a_{\phi}(440)$ only varied over 2 orders of magnitude. Improvements of remotely estimating [chl $a$ ] rely on understanding how the biooptical properties [e.g., $\left.a_{\phi}^{*}(440)\right]$ vary with changes in the bio-optical domains. Note that our data sets covered both lowand high-latitude stations with sunny, oligotrophic as well as cloudy, upwelling waters.

\section{Validation}

Unfortunately, there are no independent absorption data sets available to test the accuracy of the absorption algorithms. However, there is a global chlorophyll $a$ data set available [O'Reilly et al., 1998], and we used this data set to test our chlorophyll $a$ concentration algorithm. By applying (24) to this global data set, we got an $\mathrm{RMSD}_{\log 10}$ value of 0.191 or $\varepsilon=$ $55.2 \%\left(r^{2}=0.922, N=919\right.$; also see Figure 8$)$, which is about the same as the results of other empirical algorithms [O'Reilly et al., 1998]. If we use (25) with and without the second-order polynomial, the errors are $\mathrm{RMSD}_{\log 10}=0.200$ $(\varepsilon=58.5 \%)$ and $\mathrm{RMSD}_{\log 10}=0.228(\varepsilon=69.0 \%)$, respectively. These results and those of O'Reilly et al. [1998] demonstrate an improvement in reducing the difference between measured and modeled data by adding a second-order term in the empirical algorithms. Note that our data set used in the

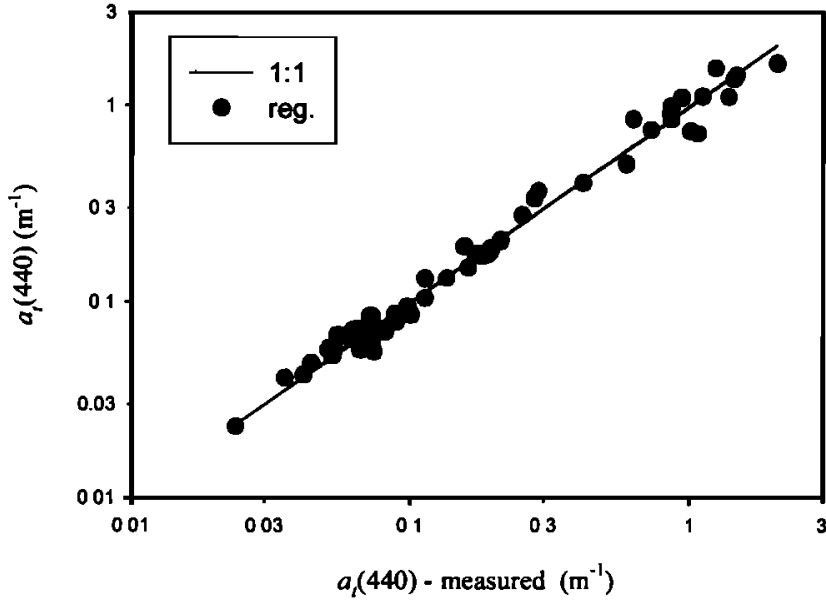

(a)

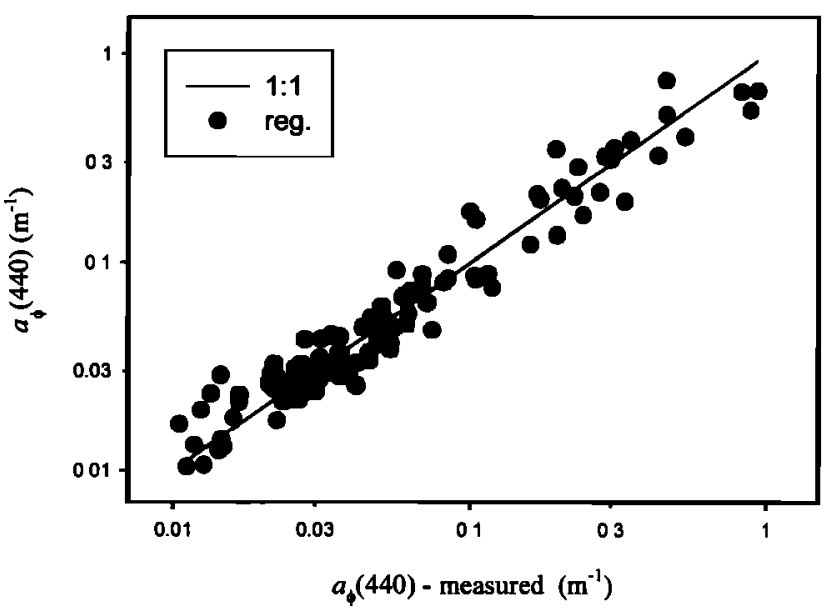

(b)

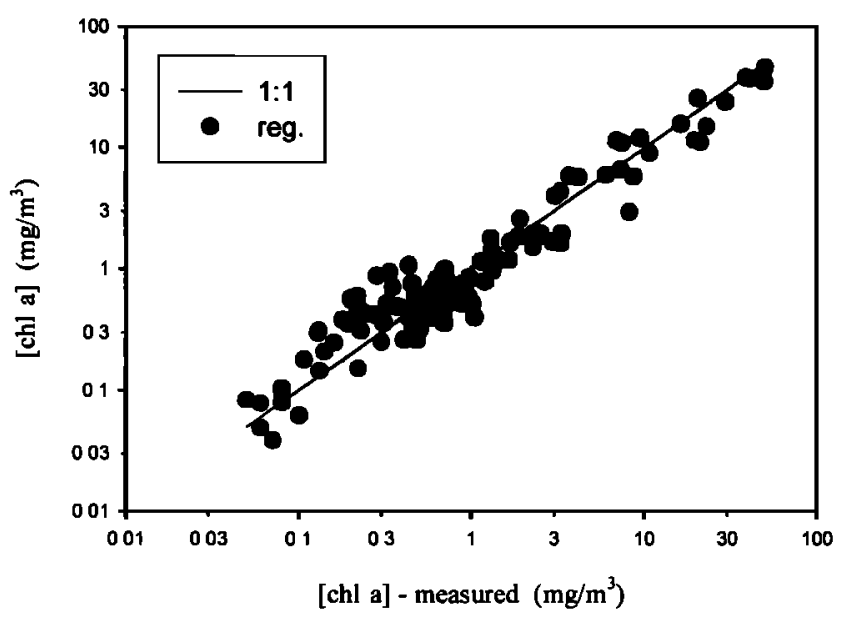

(c)

Figure 6. Measured versus regression-determined (a) $a_{t}(440)$, (b) $a_{\phi}(440)$, (c) [chl $\left.a\right]$.

algorithm development contained relatively more highchlorophyll points (34\% of them with $[\mathrm{chl} a]>1.0$ ), while the global data set contained relatively more low-chlorophyll points $(19 \%$ of them with $[\mathrm{chl} a]>1.0)$. The consistency of our chlorophyll $a$ algorithm with independent global measure- 


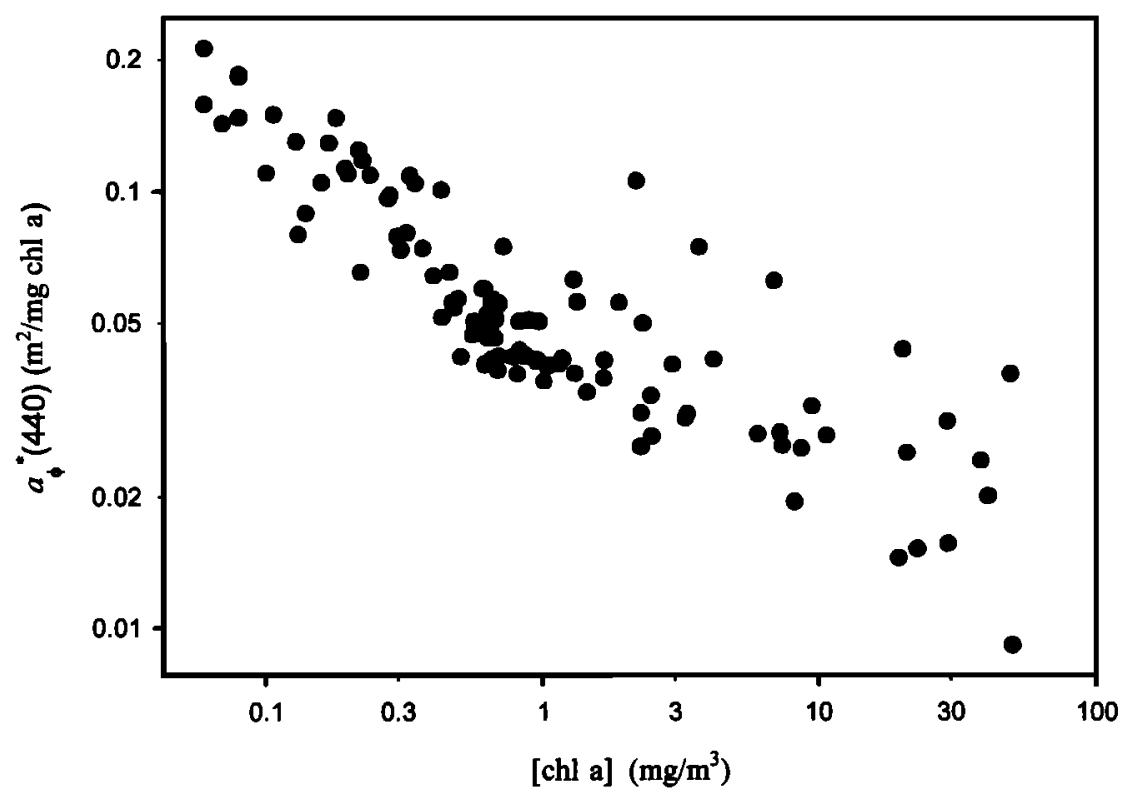

Figure 7. Values of $a_{\phi}^{*}(440)$ versus chlorophyll $a$ concentrations.

ments suggests that our absorption algorithms have been developed for waters expressing similar optical covariance as found for global waters.

\section{Summary}

Empirical algorithms for the absorption coefficients of subsurface total and phytoplankton pigments at $440 \mathrm{~nm}$ were developed, and $\mathrm{RMSD}_{\log 10}$ values as low as $0.062(15.3 \%$ for linear scale) for $a_{t}(440)$ were found. The RMSD $\mathrm{Log}_{10}$ value for absorption due to pigments was 0.111 (29.1\% for linear scale), while the $\mathrm{RMSD}_{\log 10}$ value for chlorophyll $a$ concentrations was about twice that number. The absorption algorithms developed here, though useful, require further testing with data from an even wider range of environments, while the [chl $a$ ] algorithm was tested using an independent global data set, providing an $\mathrm{RMSD}_{\log 10}$ value of 0.191 (55.2\% for linear scale, $N=919$ ).

On the basis of this data set, we can most accurately estimate the total absorption coefficient from remote sensing, followed by the absorption coefficients of individual components (e.g., pigment), and finally, the concentrations of individual constituents (e.g., [chl a]). It is not surprising that the first two are optical properties, while the last is a biological property, which includes substantial variability as a function of phytoplankton type, light, nutrients, temperature, and perhaps other environmental factors.

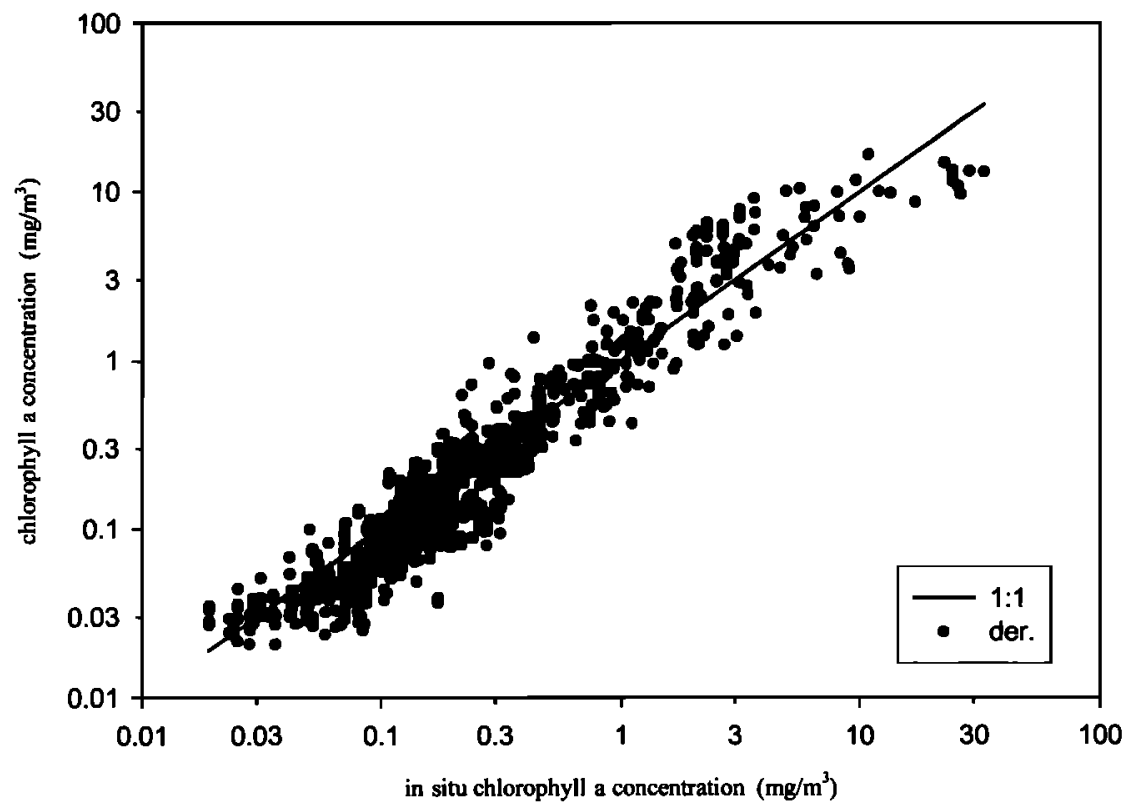

Figure 8. Comparison of algorithm-derived chlorophyll $a$ concentration to in situ values for a global data set. 
Acknowledgments. We are in debt to $J$. L. Mueller for his in-water MER measurements. Ship support was provided by R/V Suncoaster through the Florida Institute of Oceanography and R/V Bartlett and $\mathrm{R} / \mathrm{V} G$. Thompson through Naval Research Laboratory, Office of Naval Research, and NASA. Financial support was provided by ONR through grant N00014-96-I-5013 and by NASA through grants NAS531716, UPN463-11-09-04, and NAGW465. We are also very grateful to the suggestions and comments from the reviewers.

\section{References}

Aiken, J., G. F. Moore, C. C. Trees, S. B. Hooker, and D. K. Clark, The SeaWIFS CZCS-type pigment algorithm, NASA Tech. Memo., 104566,(29), 1995.

Austin, R. W., and T. J. Petzold, The determination of the diffuse attenuation coefficient of sea water using the coastal zone color scanner, in Oceanography From Space, edited by J. F. R. Gower, pp. 239-256, Plenum, New York, 1981.

Austin, R. W., and T. J. Petzold, Spectral dependence of the diffuse attenuation coefficient of light in ocean waters, Opt. Eng., 25, 471479, 1986.

Bissett, W. P., J. S. Patch, K. L. Carder, and Z. P. Lee, Pigment packaging and chlorophyll $a$ specific absorption in high-light oceanic waters, Limnol. Oceanogr., 42, 961-968, 1997.

Bricaud, A., and D. Stramski, Spectral absorption coefficients of living phytoplankton and nonalgal biogenous matter: A comparison between the Peru upwelling area and the Sargasso Sea, Limnol. Oceanogr., 35, 562-582, 1990.

Bricaud, A., A. Bedhomme, and A. Morel, Optical properties of diverse phytoplanktonic species: Experimental results and theoretical interpretation, J. Plankton Res., 10, 851-873, 1988.

Bricaud, A., M. Babin, A. Morel, and H. Claustre, Variability in the chlorophyll-specific absorption coefficients of natural phytoplankton: Analysis and parameterization, J. Geophys. Res., 100, 13,321$13,332,1995$.

Carder, K. L., and R. G. Steward, A remote-sensing reflectance model of a red tide dinoflagellate off West Florida, Limnol. Oceanogr., 30 286-298, 1985.

Carder, K. L., S. K. Hawes, K. A. Baker, R. C. Smith, R. G. Steward, and B. G. Mitchell, Reflectance model for quantifying chlorophyll $a$ in the presence of productivity degradation products, J. Geophys. Res., 96, 20,599-20,611, 1991.

Carder, K. L., Z. P. Lee, T. G. Peacock, R. G. Steward, and C. O. Davis, Aircraft algorithms for water absorption coefficients: Rain or shine (abstract), Eos Trans. AGU, 73(43), Fall Meet. Suppl., 265, 1992.

Carder, K. L., R. G. Steward, R. F. Chen, S. K. Hawes, Z. P. Lee, and C. O. Davis, AVIRIS calibration and application in coastal oceanic environments: Tracers of soluble and particulate constituents of the Tampa Bay coastal plume, Photogramm. Eng. Remote Sens., 59, 339-344, 1993

Clark, D. K., Phytoplankton algorithm for the Nimbus-7 CZCS, in Oceanography From Space, edited by J. R. F. Gower, pp. 227-238, Plenum, New York, 1981.

Garver, S. A., and D. A. Siegel, Inherent optical property inversion of ocean color spectra reflectance and its biogeochemical interpretation, 1. Time series from the Sargasso Sea, J. Geophys. Res., 102, $18,607-18,625,1997$.

Gordon, H. R., Ship perturbation of irradiance measurements at sea, 1, Monte Carlo simulations, Appl. Opt., 24, 4172-4182, 1985.

Gordon, H. R., Can the Lambert-Beer law be applied to the diffuse attenuation coefficient of ocean water?, Limnol. Oceanogr., 34, $1389-409,1989$.

Gordon, H. R., and G. C. Baynton, Radiance-irradiance inversion algorithm for estimating the absorption and scattering coefficients of natural waters: Homogeneous waters, Appl. Opt., 36, 2636-2641, 1997.

Gordon, H. R., and A. Morel, Remote Assessment of Ocean Color for Interpretation of Satellite Visible Imagery: A Review, Springer-Verlag, New York, 1983.

Gordon, H. R., R. C. Smith, and J. R. V. Zaneveld, Introduction to ocean optics, Proc. SPIE Soc. Opt. Eng., 208, 1-43, 1980.

Gordon, H. R., D. K. Clark, J. W. Brown, O. B. Brown, R. H. Evans, and W. W. Broenkow, Phytoplankton pigment concentrations in the Middle Atlantic Bight: Comparison of ship determinations and CZCS estimates, Appl. Opt., 22, 20-36, 1983.
Gordon, H. R., O. B. Brown, R. H. Evans, J. W. Brown, R. C. Smith, K. S. Baker, and D. K. Clark, A semi-analytic radiance model of ocean color, J. Geophys. Res., 93, 10,909-10,924, 1988.

Hoge, F. E., and P. E. Lyon, Satellite retrieval of inherent optical properties by linear matrix inversion of oceanic radiance models: An analysis of model and radiance measurement errors, J. Geophy. Res., $101,16,631-16,648,1996$.

Holm-Hansen, $\mathrm{O}$., and B. Riemann, Chlorophyll a determination: improvements in methodology, Oikos, 30, 438-447, 1978.

Kirk, J. T. O., Attenuation of solar radiation in scattering-absorbing waters: A simplified procedure for its calculation, Appl. Opt., 23, 3737-3739, 1984.

Kirk, J. T. O., Volume scattering function, average cosines, and the underwater light field, Limnol. Oceanogr., 36, 455-467, 1991.

Kishino, M., M. Takahashi, N. Okami, and S. Ichimura, Estimation of the spectral absorption coefficients of phytoplankton in a thermally stratified sea, Bull. Mar. Sci., 37, 634-642, 1985.

Lee, Z. P., Visible-infrared remote-sensing model and applications for ocean waters, Ph.D. dissertation, Dep. of Mar. Sci., Univ. of S. Fl., St. Petersburg, 1994.

Lee, Z. P., K. L. Carder, S. K. Hawes, R. G. Steward, T. G. Peacock and $\mathrm{C}$. O. Davis, A model for interpretation of hyperspectral remote sensing reflectance, Appl. Opt., 33, 5721-5732, 1994.

Lee, Z. P., K. L., Carder, R. G. Steward, and M. J. Perry, Estimating primary production at depth from remote sensing, Appl. Opt., 35, 463-474, 1996a.

Lee, Z. P., K. L. Carder, T. G. Peacock, C. O. Davis, and J. L. Mueller, Method to derive ocean absorption coefficients from remote-sensing reflectance, Appl. Opt., 35, 453-462, 1996b.

Lee, Z. P., K. L. Carder, R. G. Steward, T. G. Peacock, C. O. Davis, and J. L. Mueller, Remote-sensing reflectance and inherent optical properties of oceanic waters derived from above-water measurements, Proc., SPIE Soc. Opt. Eng., 2963, 160-166, 1996c.

Mitchell, B. G., and D. A. Kiefer, Chl $a$ specific absorption and fluorescence excitation spectra for light limited phytoplankton, Deep Sea Res., Part A, 35, 635-663, 1988.

Moore, L. R., R. Goericke, and S. W. Chisholm, Comparative physiology of Synchococcus and Prochlorococcus: Influence of light and temperature on growth, pigments, fluorescence and absorptive properties, Mar. Ecol. Prog. Ser., 116, 259-275, 1995.

Morel, A., Optical modeling of the upper ocean in relation to its biogenous matter content (Case 1 waters), J. Geophys. Res., 93, $10,749-10,768,1988$.

Morel, A., and A. Bricaud, Theoretical results concerning light absorption in a discrete medium, and application to specific absorption of phytoplankton, Deep Sea Res., Part A, 28, 1375-1393, 1981.

Morel, A., Optical properties of oceanic case 1 waters, revisited, Proc. SPIE Soc. Opt. Eng., 2963, 108-114, 1996.

Morel, A., and B. Gentili, Diffuse reflectance of oceanic waters, 2, Bi-directional aspects, Appl. Opt., 32, 6864-6879, 1993.

Morel, A., and L. Prieur, Analyse spectrale des coefficients d'attenuation diffuse, d'absorption et de retrodiffusion pour diverses regions marines, Rep. 17, p. 175, Cent. Rech. Oceanogr., Villefranche-sur-Mer, France, 1975.

Morel, A., and L. Prieur, Analysis of variations in ocean color, Limnol. Oceanogr., 22, 709-722, 1977.

Mueller, J. L., and R. W. Austin, Ocean optics protocols for SeaWiFS validation, NASA Tech. Memo., 104566, 1992.

Mueller, J. L., and C. C. Trees, Evaluation of coastal zone color scanner diffuse attenuation coefficient algorithms for application to coastal waters, Proc. SPIE Soc. Opt. Eng., 1302, 72-78, 1990.

Nelson, J. R., and C. Y. Robertson, Detrital spectral absorption: Laboratory studies of visible light effects on phytodetritus absorption, bacterial spectral signal, and comparison to field measurements, $J$. Mar. Res., 5I, 181-207, 1993.

O'Reilly, J., S. Maritorena, B. G. Mitchell, D. Siegel, K. L. Carder, S. Garver, and C. McClain, Ocean color chlorophyll algorithms for SeaWiFS, J. Geophys. Res., 103, 24,937-24,954, 1998.

Platt, T., and S. Sathyendranath, Oceanic primary production: Estimation by remote sensing at local and regional scales, Science, 241, 1613-1620, 1988.

Pope, R., and E. Fry, Absorption spectrum (380-700 nm) of pure waters, II, Integrating cavity measurements, Appl. Opt., 36, 87108723, 1997.

Preisendorfer, R. W., Hydrologic optics, vol. 1, Introduction, NTIS. PB-259 793/8ST, Natl. Tech. Inf. Serv., Springfield, Va., 1976. 
Roesler, C. S., and M. J. Perry, In situ phytoplankton absorption, fluorescence emission, and particulate backscattering spectra determined from reflectance, J. Geophys. Res., 100, 13,279-13,294, 1995.

Roesler, C. S., M. J. Perry, and K. L. Carder, Modeling in situ phytoplankton absorption from total absorption spectra in productive inland marine waters, Limnol. Oceanogr., 34, 1510-1523, 1989.

Sathyendranath, S., L. Lazzara, and L. Prieur, Variations in the spectral values of specific absorption of phytoplankton, Limnol. Oceanogr., 32, 403-415, 1987.

Smith, R. C., and K. S. Baker, Optical properties of the clearest natural waters, Appl. Opt., 20, 177-184, 1981.

Smith, R. C., B. B. Prezelin, R. R. Bidigare, and K. S. Baker, Bio optical modeling of photosynthetic production in coastal waters, Limnol. Oceanogr., 34, 1524-1544, 1989.

Stramski, D., and A. Morel, Optical properties of photosynthetic pi- coplankton in different physiological states as affected by growth irradiance, Deep Sea Res., Part A, 37, 245-266, 1990.

Voss, K. J., A spectral model of the beam attenuation coefficient in the ocean and coastal areas, Limnol. Oceanogr., 37, 501-509, 1992.

Yentsch, C. S., and D. W. Menzel, A method for the determination of phytoplankton chlorophyll and phaeophytin by fluorescence, Deep Sea Res. Oceanogr. Abstr., 10, 221-231, 1963.

K. L. Carder, Z. P. Lee, J. S. Patch, T. G. Peacock, and R. G. Steward, Department of Marine Science, University of South Florida, St. Petersburg, FL 33701. (e-mail: zplee@marine.usf.edu)

C. O. Davis, Naval Research Laboratory, Washington, DC 20375.

(Received October 31, 1997; revised April 16, 1998; accepted June 5, 1998.) 